\title{
Changes in Peer and Parent Influence During Adolescence: Longitudinal Versus Cross-Sectional Perspectives on Smoking Initiation
}

\author{
Laurie Chassin and Clark C. Presson \\ Arizona State University \\ Daniel Montello \\ Arizona State University
}

\author{
Steven J. Sherman \\ Indiana University \\ John McGrew \\ Indiana University
}

\begin{abstract}
The current study used a longitudinal design to investigate age-related changes in the magnitude of peer and parent influences on adolescent cigarette smoking. Both peer and parent influences were significant predictors of subsequent transitions to higher levels of smoking. However, unlike previous cross-sectional research, the magnitude of peer and parent influences did not significantly vary across the 6 th- to 11 th-grade levels. Additional analyses were undertaken to explore possible explanations for the differences between results produced by cross-sectional and longitudinal approaches. Implications for the study of transitions across the life span are discussed.
\end{abstract}

Many researchers have pointed to the significance of peer and parent influences on a wide range of behaviors during adolescence. For example, peers and parents have been found to influence moral socialization (Brody \& Shaffer, 1982), adolescent "problem behaviors" (Jessor \& Jessor, 1977), and adolescents" adaptation to environmental transition (Chiriboga, 1984). In the field of substance use, previous research has been reviewed by Glynn (1981), who concluded that both peer and parent influences were important and that their relative importance varied with the use of different substances. Family and peer influences were found to be nearly equivalent for alcohol use, peer influences predominated for marijuana use, and family influences predominated for illicit drugs other than marijuana. It is thus clear that both peer and parent influences play important roles in determining a number of important adolescent behaviors.

The present article addresses the issue of the variation in the importance of peer and parent influence across early and middle adolescence. This topic has both theoretical and practical importance. Theoretically, adolescence has been viewed as a time of increasing peer influence (Berndt, 1979). Some theorists view these peer influences as replacing earlier parental influence (Ausubel, Montemayor, \& Svajian, 1977). Kandel and Lesser (1972) referred to these models as hydraulic because they portray a constant level of influence by the social environment with increasing peer influence balancing decreasing parental influence. In contrast to these hydraulic models, other theories argued that the level of social influence is not necessarily constant. Rather, levels of parental and peer influence might increase or decrease independently through adolescence. In this view, adolescents may

This research was supported by Grant HD 13449 from the National Institute of Child Health and Human Development.

The authors thank the Monroe County Public Schools for their participation, and Stanley Azen for his thoughtful comments.

Correspondence concerning this article should be addressed to Laurie Chassin, Department of Psychology, Arizona State University, Tempe, Arizona 85287. remain influenced by both their parents and their peers, although the relative importance of parents and peers may vary with different behaviors or issues (Brittain, 1963; Brody \& Shaffer, 1982; Kandel \& Lesser, 1972).

Aside from its theoretical significance, the magnitude of peer and parent influences as a function of age becomes a matter of practical importance when adolescent problem behaviors are considered, specifically when intervention programs are developed to deter adolescents from substance use and abuse. These programs often focus on combating "peer pressure" with the implicit assumption that peer influences weigh heavily on adolescents' behavioral decisions (see Flay, d'Avernas, Best, Kersall, \& Ryan, 1983 for a review). However, at least within the field of substance abuse, some researchers believe that the potential importance of parental influence has been overlooked (Clayton, 1979). An understanding of parental and peer influences on adolescents' substance use might suggest directions for the focus of intervention programs. In addition, such findings might suggest that the focus of these programs should change across the different stages of adolescence as the magnitude of importance of peer and parent influences changes. Thus, such an understanding has practical importance for designing effective interventions into adolescent problem behaviors as well as theoretical importance for investigating hydraulic models of adolescent social development.

Previous research has in fact suggested that parent and peer influences on substance use vary with the age of the adolescent. Biddle, Bank, and Marlin (1980b) found that adolescent alcohol use was most strongly related to parental norms for younger adolescents (mean age $=12.9$ years), was most strongly related to both peer norms and peer modeling for middle adolescents (mean age $=15.2$ years), and was related to both parent and peer norms for older adolescents (mean age $=18.4$ years). Biddle et al. (1980b) suggested that parent influence on alcohol use temporarily recedes in importance in middle adolescence but re-emerges in older adolescence.

In the area of adolescent cigarette smoking, both peer and parent influences have been reported to be important motivators 
of smoking decisions (Flay et al., 1983). However, less is known about whether peer and parent influences change with age. Levitt (1971) found that younger subjects (5th graders) reported greater parent influence on smoking than did older subjects (high school students). In contrast, the greatest reported peer influence was found for middle adolescents (8th graders). Unfortunately, Levitt's study only measured subjects' perceptions of the extent of peer and parent influence rather than actual relations between peer and parent variables and adolescents' smoking. Chassin et al. (1981) studied intentions to begin to smoke among nonsmoking adolescents in both middle school and high school. Correlations between intentions to smoke and friends' smoking were stronger at middle than at high school grade levels. In addition, smoking intentions were weakly related to parental smoking at middle school ages and unrelated to parental smoking at high school ages. These data suggest that both peer and parent influences on adolescent smoking initiation might be strongest at early adolescence. However, this study measured adolescents' intentions to smoke rather than their actual smoking behavior.

Krosnick and Judd (1982) investigated peer and parent influence in relation to smoking behavior among 11- and 14-yearolds. They found that parent influence did not significantly differ at the two age levels, although peer influence was stronger for older subjects. Examining the relative importance of peer and parent influence, they found that the two were equally important for 11 -year-olds, although peer influences outweighed adult influences for 14-year-olds.

Krosnick and Judd's (1982) study brought an increased methodological sophistication to the study of peer and parent influences on adolescent cigarette smoking. However, as the authors themselves note, there are still significant limitations to the study that leave important questions unresolved. The current study builds on Krosnick and Judd's earlier work with the aim of providing a more comprehensive picture of the role of parent and peer influences on adolescent smoking.

First, and most important, Krosnick and Judd's study was based on a cross-sectional sample of both nonsmokers and smokers. Such a design cannot distinguish the antecedents of smoking from the consequents. Chassin, Presson, and Sherman (1984) demonstrated that changes in adolescents' perceived social environments both preceded and followed from transitions in their smoking status. Thus, any age changes in cross-sectional correlates of smoking might reflect developmental changes in either the antecedents or consequents of adolescent smoking. A longitudinal study is necessary to separate out these possibilities. A cross-sectional study cannot follow adolescents as they make the transition to higher levels of smoking. Only when these transitions are examined directly can strong inferences about the factors inducing transitions be made.

The present study extends previous work in another important way. Most researchers believe that cigarette smoking is best conceptualized as a series of stages, with initiation and maintenance having very different determinants (Leventhal \& Cleary, 1980). For example, Flay et al. (1983) found that family influences were important to early preparation stages of smoking although peer factors were important to later stages. These differences are obscured in a cross-sectional design because the factors that produce smoking initiation are confounded with those responsible for smoking maintenance. To solve this problem, initial smoking transitions must be studied separately from later transitions from experimental to regular smoking.

The current study is based on a cohort-sequential design in which subjects at different ages were followed over a one-year time period. Thus, the importance of peer and parent variables to actual smoking transition can be studied. Moreover, the factors that predict the initial transition from never smoker to trier can be studied separately from those that predict the transition from trier to regular smoker. Thus, the current study can examine the role of parent and peer influences separately at different stages of the smoking acquisition process.

In addition to studying the smoking acquisition process longitudinally, the current study expanded the age range of adolescents who were considered (6th-11 th graders) and also examined the possibility of sex differences in peer and parent influences, to see whether girls or boys were particularly susceptible to social influence. Huba and Bentler (1980) found that peer models were more strongly related to substance use among girls than among boys. Therefore, the current analyses examined the importance of peer and parent influence across sex as well as across age.

The current study also considered several different kinds of peer and parent influences on adolescent smoking acquisition because the magnitude of parent and peer influence may vary with the type of influence that is studied (Clasen \& Brown, 1985). Biddle, Bank, and Marlin (1980a) found that parental attitudes generally outweighed peer attitudes as influences on adolescent drinking. However, peer modeling influences outweighed parental modeling influences. Thus, different types of peer and parent influence must be considered. The current study investigated a range of social influences derived from Jessor and Jessor's (1977) problem behavior theory. This theory has been used to predict the onset of adolescent problem behaviors (including substance use) from both proximal and distal social influences. Based on this theoretical model, the current study assessed peer and parent smoking models, peer and parent attitudes toward the adolescents' smoking, the perceived strictness of peers and parents, the perceived supportiveness of peers and parents, and the perceived expectations of peers and parents for the adolescents' general and academic success.

In short, the current study investigated peer and parent influences on the actual smoking transitions of adolescents. The study sought to discover whether the influence of peers or parents on smoking transition differed at different ages or differed for boys and girls. By using a longitudinal design and by examining the transitions of initial never smokers and initial triers separately, the factors that influence initiation of smoking were distinguished from those that influence the transition from trier to regular smoker.

\section{Method}

\section{Subjects}

At Time 1 of measurement (1982), 3,819 6th-11th graders in a midwestern county school system completed questionnaires as part of a larger study of adolescent cigarette smoking. Demographic figures show that the community under investigation was predominantly white $(96 \%)$, and was $17 \%$ rural, $57 \%$ suburban, and $26 \%$ urban. The influence of a large university population is reflected in the educational status of parents; $75 \%$ of the parents had completed high school and $38 \%$ had attained a bachelor's or higher degree. 
One year later the questionnaires were again administered to 7 th- 12 th graders, and $69.7 \%$ of the original sample completed them. This retention rate is quite comparable to other studies that have used one-year longitudinal follow-ups (Josephson \& Rosen, 1978).

Subjects were divided into smoking status groups based on their response to a 6-item scale of self-reported smoking: I have never smoked a cigarette, not even a few puffs, never smoker; I have smoked a cigarette or a few cigarettes "just to try," but not in the past month, trier; I no longer smoke but in the past I was a regular smoker, exsmoker; I smoke regularly, but not more than one cigarette a month; I smoke regularly, but not more than one cigarette a week; and I smoke more than one cigarette a week.

The current longitudinal analyses focus on the question of smoking acquisition. Therefore, only subjects who were never smokers or triers at the first time of measurement (and who were present at the second time of measurement) were included in the longitudinal analyses. In addition, subjects were excluded if they failed to report a smoking status or if they were exsmokers at the second time of measurement. There were 1,459 intial never smokers and 669 initial triers who met the inclusion criteria.

\section{Procedure}

Questionnaires were administered during a regular class period by members of a research team who were not connected with the school system. Subjects were assured that their responses would be kept confidential. The procedures for the two administrations ( 1 year apart) were identical.

In order to improve the validity of adolescents' self-reports of smoking behavior, the current study used a bogus pipeline procedure (Evans, Hansen, \& Mittelmark, 1977), in which each subject was asked to lick a strip of paper, seal it in an envelope, and write their questionnaire code number on the envelope. Subjects were told that chemical analysis of saliva can accurately detect metabolites of nicotine, and therefore detect smoking.

\section{Operationalization of Variables}

All variables were part of a larger questionnaire used to study adolescent cigarette smoking initiation. The questionnaire has been described in detail elsewhere (Chassin et al., 1981). Variables were operationalized as follows.

Parent and peer smoking models. Parental smoking was assessed by two items: "My mother (father) smokes cigarettes." Parental smoking could range from 0 to 2 . Peer smoking was assessed by a single item, "How many of your five closest friends smoke cigarettes?" Because $90 \%$ of the initial never smokers or triers responded 0,1 , or 2 to this item, it was recoded as 0 (no friends), 1 ( 1 friend), or 2 ( $2-5$ friends), thus making its range comparable to the parental models variable.

Parent and peer attitudes toward the adolescent's smoking. Subjects' perceptions of their parents' and friends' attitudes toward their smoking were measured by two items: "My friends think that I should smoke cigarettes" and "My parents think that I should smoke cigarettes." Responses were given on a 5-point scale, ranging from strongly agree to strongly disagree.

Parental and peer expectations. The items for the last three sets of variables (expectations, supportiveness, and strictness) were taken from Schlegel and DiTecco's (1978) empirically shortened version of the Jessor and Jessor (1977) questionnaire. Parental and peer expectations concerning subjects' academic and general success were assessed by two items each (e.g., "Is it important to your friends that you do well in school?").

Perceived supportiveness of parents and peers. The perceived supportiveness of parents and peers was assessed by two items each (e.g., "When you need help with some problems you're having, do your parents try to understand and give you the help you need?").

Perceived strictness of parents and peers. Perceived parent and peer strictness was assessed by two items each (e.g., "Compared to other parents, how strict would you say your parents are with you?"). Responses to these items were given on 5-point scales.

\section{Attrition Bias}

Analyses were undertaken to test for attrition bias among the initial never smokers and triers who were included in the longitudinal analyses. Those who were not tested at Time 2 (dropouts) were compared with those who were tested at both times (stayers), using a series of univariate $F$ tests. For the most part, the two groups were quite similar on measures of the 10 variables at Time 1 (a parent and a peer version of each of the 5 variables). Among the never smokers, $24 \%$ of the subjects who participated in the first year of the study did not participate in the second year. These dropouts reported significantly more friends who smoked $(p<$ .05 ), as well as lower levels of parental expectations for academic and general success $(p<.01)$. These comparisons suggest that there may have been some biased attrition among never smokers, in that subjects in more prosmoking environments were more likely to drop out. The drop-out rate among triers was $33 \%$, somewhat higher than the rate among never smokers. This differential dropout rate for never smokers and triers may indicate a greater attrition rate for the more "deviance prone" adolescents. Comparing triers who dropped out with those who remained, there were several significant differences. Triers who dropped out had a significantly greater number of smoking friends $(p<.01)$ and lower parental expectations for academic and general success $(p<.05)$. In addition, dropouts reported less negative attitudes toward smoking by both parents and peers ( $p s<.05$ ). The differences between dropouts and stayers for both never smokers and triers are not large. However, as in any longitudinal study requiring multiple measurements in a school setting, some caution must be taken in generalizing results. More deviant adolescents are likely to be underrepresented in the sample.

\section{Results}

\section{Longitudinal Prediction of Smoking Transition}

A series of logistic regression analyses (Everitt \& Dunn, 1983; Kriska \& Milligan, 1982) were used to predict transition in smoking status from parent and peer variables measured one year earlier. In each case the criterion variable was the subject's transition in smoking status as a dichotomy (no change in smoking status vs. increase to a higher level of smoking). Decreases in smoking status were not included.

For each logistic regression, the model predicted transition from subjects' sex, grade at Time 1, a peer variable, its parent equivalent, two-way interactions between sex and peer and sex and parent variables, and two-way interactions between grade and peer and grade and parent variables (a total of eight terms in each model). For example, the effects of smoking models were assessed in a logistic regression using sex, grade, number of smoking parents, number of smoking friends, the interaction between sex and smoking parents, the interaction between sex and smoking friends, the interaction between grade and smoking parents, and the interaction between grade and smoking friends. Because this article focuses on age-related changes in parent and peer influences, the terms of critical interest are the interactions between grade and peer and grade and parent variables.

Subjects' scores on the variables were standardized so that the variances of all of the continuous independent variables were equal and were centered to avoid nonessential multicollinearity between main effects and interactions (Pedhazur, 1982). Logistic regressions were performed for the pairs of peer/parent variables 
Table 1

Effects of Peer and Parent Variables and Their Interactions With Sex and Grade on Subsequent Smoking Transitions

\begin{tabular}{|c|c|c|c|c|c|c|c|c|c|c|}
\hline \multirow[b]{2}{*}{ Effect } & \multicolumn{2}{|c|}{ Modeling } & \multicolumn{2}{|c|}{ Attitudes } & \multicolumn{2}{|c|}{ Supportiveness } & \multicolumn{2}{|c|}{ Expectations } & \multicolumn{2}{|c|}{ Strictness } \\
\hline & $\begin{array}{l}\text { Coeffi- } \\
\text { cient }^{a}\end{array}$ & $\begin{array}{c}\text { Coeffi- } \\
\text { cient } / S E^{\mathrm{b}}\end{array}$ & $\begin{array}{c}\text { Coeffi- } \\
\text { cient }\end{array}$ & $\begin{array}{c}\text { Coeffi- } \\
\text { cient } / S E\end{array}$ & $\begin{array}{c}\text { Coeffi- } \\
\text { cient }\end{array}$ & $\begin{array}{c}\text { Coeffi- } \\
\text { cient } / S E\end{array}$ & $\begin{array}{c}\text { Coeffi- } \\
\text { cient }\end{array}$ & $\begin{array}{c}\text { Coeffi- } \\
\text { cient } / S E\end{array}$ & $\begin{array}{c}\text { Coeffi- } \\
\text { cient }\end{array}$ & $\begin{array}{c}\text { Coeffi- } \\
\text { cient } / S E\end{array}$ \\
\hline
\end{tabular}

\begin{tabular}{|c|c|c|c|c|c|c|c|c|c|c|}
\hline \multicolumn{11}{|c|}{ Initial never smokers } \\
\hline $\begin{array}{l}\text { Peer } \\
\text { Parent } \\
\text { Sex } \times \text { Peer } \\
\text { Sex } \times \text { Parent } \\
\text { Grade } \times \text { Peer } \\
\text { Grade } \times \text { Parent }\end{array}$ & $\begin{array}{r}.23 \\
.24 \\
.02 \\
.20 \\
-.06 \\
-.05\end{array}$ & $\begin{array}{l}3.84^{* * * *} \\
3.38^{* * * *} \\
0.28 \\
2.94^{* * *} \\
-1.04 \\
-0.65\end{array}$ & $\begin{array}{r}.12 \\
.04 \\
-.03 \\
.04 \\
-.14 \\
.10\end{array}$ & $\begin{array}{r}1.34 \\
0.51 \\
-0.40 \\
0.44 \\
-1.42 \\
0.99\end{array}$ & $\begin{array}{r}.13 \\
-.21 \\
-.02 \\
-.02 \\
-.09 \\
.03\end{array}$ & $\begin{array}{l}1.54 \\
-2.89^{* *} \\
-0.22 \\
-0.28 \\
-1.10 \\
0.45\end{array}$ & $\begin{array}{r}-.20 \\
.10 \\
-.11 \\
.08 \\
.01 \\
-.05\end{array}$ & $\begin{array}{r}-2.61^{* *} \\
1.24 \\
-1.45 \\
1.06 \\
0.18 \\
-0.58\end{array}$ & $\begin{array}{r}.03 \\
.09 \\
-.09 \\
-.01 \\
-.07 \\
-.16\end{array}$ & $\begin{array}{r}0.35 \\
1.19 \\
-1.20 \\
-0.14 \\
-0.92 \\
-2.24^{*}\end{array}$ \\
\hline \multicolumn{11}{|c|}{ Initial triers } \\
\hline $\begin{array}{l}\text { Peer } \\
\text { Parent } \\
\text { Sex } \times \text { Peer } \\
\text { Sex } \times \text { Parent } \\
\text { Grade } \times \text { Peer } \\
\text { Grade } \times \text { Parent }\end{array}$ & $\begin{array}{r}.31 \\
.20 \\
.01 \\
.23 \\
-.08 \\
-.02\end{array}$ & $\begin{array}{l}2.71^{* * * *} \\
1.56 \\
0.09 \\
1.86 \\
-0.73 \\
-0.13\end{array}$ & $\begin{array}{r}.24 \\
.07 \\
.31 \\
-.04 \\
.07 \\
-.14\end{array}$ & $\begin{array}{r}1.68 \\
0.53 \\
2.08^{*} \\
-0.31 \\
0.51 \\
-0.94\end{array}$ & $\begin{array}{r}.46 \\
-.56 \\
-.24 \\
-.02 \\
-.02 \\
.02\end{array}$ & $\begin{aligned} & 3.04^{* * *} \\
&-4.56^{* * *}-1.61 \\
&-0.18 \\
&-0.11 \\
& 0.14\end{aligned}$ & $\begin{array}{r}.01 \\
-.12 \\
-.40 \\
-.15 \\
.10 \\
-.24\end{array}$ & $\begin{array}{c}0.04 \\
-0.89 \\
-2.84^{* *} \\
-1.13 \\
0.68 \\
-1.80\end{array}$ & $\begin{array}{r}-.15 \\
.09 \\
-.22 \\
-.15 \\
.01 \\
.02\end{array}$ & $\begin{array}{r}-1.14 \\
0.71 \\
-1.62 \\
-1.21 \\
0.02 \\
0.19\end{array}$ \\
\hline
\end{tabular}

- Coefficients based on maximum likelihood estimates. ${ }^{b}$ Coefficient divided by standard error. These ratios can be interpreted as $t$ statistics.

${ }^{*} p<.05 .^{* *} p<.01$. $^{* * *} p<.001$.

described earlier, that is, smoking models, attitudes toward the subjects' smoking, perceived supportiveness, perceived strictness, and perceived expectations. Regressions were performed separately for initial never smokers and initial triers, producing a total of 10 analyses. The regression coefficients based on maximum likelihood estimates for the main effects of peer and parent variables and their interaction with grade and sex are presented in Table 1.

\section{Peer and Parent Smoking Models}

For initial never smokers, those with more smoking parents and more smoking peers were more likely to begin to smoke. There was also a significant Sex $\times$ Parental Smoking interaction. When examined separately by sex, the effects of smoking parents was significant only for girls $(t=6.58, p<.001)$. There were no significant interactions involving grade.

Among initial triers, those with more smoking friends were more likely to become regular smokers. There were no significant interactions involving sex or grade.

\section{Peer and Parental Attitudes Toward the Subject's Smoking}

Among initial never smokers, there were no significant effects of peer or parent attitudes on later smoking transition, and there were no significant interactions.

Among initial triers, there was a significant interaction of peer attitudes with subject sex. Considered separately by sex, friends' attitudes affected subsequent transition only for girls $(t=4.27$, $p<.001$ ). Girls who saw their friends as more positive toward their smoking were more likely to become regular smokers at Time 2 . There were no significant interactions involving grade.

\section{Perceived Supportiveness of Peers and Parents}

For initial never smokers, those who saw their parents as more supportive were less likely to begin to smoke. There were no significant interactions involving grade or sex.

For initial triers, those who saw their parents as more supportive were less likely to become regular smokers. However, those who saw their friends as more supportive were more likely to become regular smokers. There were no significant interactions involving grade or sex.

\section{Peer and Parent Expectations}

Among initial never smokers, those who saw their friends as having higher expectations about academic and general success were less likely to begin to smoke. There were no significant interactions involving grade or sex.

Among initial triers, there was an interaction of friends' expectations with subjects' sex such that friends' expectations affected transition in opposite ways for girls and boys. Girls whose friends had lower expectations of them were more likely to become regular smokers later $(t=-3.87, p<.001)$. Boys whose friends had higher expectations of them were more likely to become regular smokers $(t=3.34, p<.01)$. There were no significant interactions involving grade.

\section{Perceived Strictness of Peers and Parents}

Among initial never smokers, there was a significant interaction of subjects' grade level with parental strictness. To explore this interaction, the effects of parental strictness were examined separately at three grade levels (6th-7th, 8 th -9 th, and 10 th- 11 th). Parental strictness significantly affected transition in opposite ways for youngest and oldest subjects. For the youngest subjects 
Table 2

Regression Coefficients for the Effects of Peer and Parent Variables and Their Interactions With Sex and Grade on the Cross-Sectional Prediction of Smoking Status

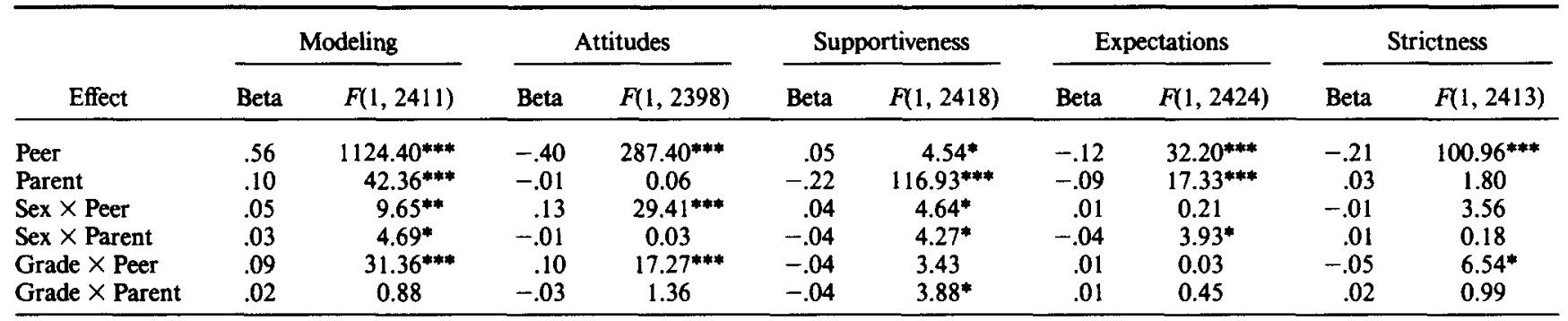

Note. Analysis combines abstainers, triers, monthly, weekly, and more-than-weekly smokers. Exsmokers were eliminated. The numerical values of the coefficients in Tables 1 and 2 should not be compared directly because different analyses were used. The patterns of significance can be compared. ${ }^{*} p<.05$. ${ }^{* *} p<.01$. $^{* * *} p<.001$.

(6th-7th graders), those with stricter parents were actually more likely to begin to smoke ( $t=2.65, p<.01)$. For the oldest subjects (10th-11th graders), those with stricter parents were less likely to begin to smoke $(t=-3.04, p<.01)$. Parental strictness did not significantly affect transition for the middle group (8th-9th graders). There were no significant interactions involving subject sex.

Among initial triers, there were no significant effects of parental or peer strictness on transition, and there were no significant interactions involving grade or sex.

\section{Cross-Sectional Analyses}

A striking finding of the longitudinal analyses was the lack of significant interactions between subjects' grade level and either peer or parent variables. Out of a possible 20 interactions, only one was significant (not different from what would be expected by chance alone). This was surprising in view of previous crosssectional research that reported age-related changes in peer influences on cigarette smoking. In particular, Krosnick and Judd (1982) found that peer modeling influences increased with age at levels corresponding to our 6 th- 7 th and 8 th-9th graders.

To explore the discrepancy between the current data and previous cross-sectional research, a series of additional analyses were undertaken. Specifically, we wanted to see whether or not the pattern of age-related changes found by Krosnick and Judd (1982) would appear in our data analyzed cross sectionally.

The first cross-sectional analysis used a series of hierarchical multiple regressions to predict subjects' smoking status in Year 2 from Year 2 variables. To ensure that the subject populations were similar for the longitudinal and cross-sectional analyses, only subjects who were present in both years of data collection were included. These analyses used the same predictor variables and standardization procedures as the longitudinal analyses described. However, here the criterion variable was current smoking status (five levels-never smoker, trier, monthly smoker, weekly smoker, and more-than-weekly smoker). Main effects were entered in Step 1 and interaction terms in Step 2. As before, the terms of critical interest are the interactions between grade and peer and between grade and parent variables.

The most important data concern the peer and parent modeling variables and the parental attitude variable, because these were the factors included in Krosnick and Judd's (1982) study. The results exactly replicated those of Krosnick and Judd. There was a significant interaction between grade and the number of smoking friends (see Table 2). The effect of smoking friends increased with grade level (betas of .50, .63, and .61, for Grades 6-7, 8-9, and 10-11, considered separately). There were no significant interactions involving grade and either parental models or parental attitudes. These results were exactly as obtained by Krosnick and Judd's (1982) earlier study.

The current study also included peer and parent variables that were not investigated by Krosnick and Judd (1982). The crosssectional analyses of these variables produced three additional interactions involving grade (see Table 2). There was a significant interaction between grade and parental supportiveness, such that the effect of parental supportiveness decreased with age (coefficients were $-.26,-.23$, and -.20 for the 6 th -7 th, 8 th -9 th, and 10th-11th graders, respectively, considered separately). In all cases, adolescents with more supportive parents were less likely to be smokers.

There was also a significant interaction between grade and friends' strictness, such that the effect of friends' strictness increased with grade (betas of $-.19,-.22$, and -.24 for 6 th -7 th, 8th-9th, and 10th-11th graders, respectively, considered separately). In all cases, adolescents with less strict friends were more likely to be smokers.

There was also a significant interaction between grade and friends' attitudes, such that the effect of friends' attitudes increased with age (betas were $.35, .43$, and .48 for 6 th- 7 th graders, 8th-9th graders, and 11 th-12th graders, respectively, considered separately). In all cases, adolescents whose friends were more positive about their smoking were more likely to be smokers.

These cross-sectional analyses thus produced several significant grade interactions (including the important Grade $\times$ Peer Modeling interaction seen by Krosnick \& Judd, 1982) that were absent from the longitudinal data. Additional cross-sectional analyses were undertaken to illuminate this discrepancy.

The longitudinal and cross-sectional analyses (reported in Tables 1 and 2) differed in two major ways. First, they differed in the criterion variable, which was dichotomous in the longitudinal analysis and had five levels in the cross-sectional analysis. However, reanalyses of the longitudinal data predicting Time 2 smoking status as a five-level variable replicated the logistical regression 
in that no grade interactions were found. Thus, differences in the criterion variable cannot explain the differences between the cross-sectional and longitudinal findings.

A second difference between the longitudinal and cross-sectional analyses is the heterogeneity of the subject populations. The longitudinal analyses were done separately for initial never smokers and initial triers (homogeneous populations), whereas the cross-sectional analyses included all subjects, long-term smokers as well as nonsmokers and triers. To see whether this homogeneity was an important factor affecting the presence or absence of grade interactions, the cross-sectional multiple regressions described in Table 2 were run separately for subjects who were never smokers at Year 1 and for subjects who were triers at Year 1.

Cross-sectional analyses using only the initial never smokers produced 1 significant interaction involving grade (out of 10 possible interactions). There was a significant interaction between grade and parental attitudes $(F=9.02, p<.003)$. The effect of parental attitudes was strongest at the middle grade level (coefficients of $-.07, .15$, and -.08 , respectively). For the middle age range, adolescents whose parents were more positive about smoking were more likely to be smokers. For the youngest and oldest groups, adolescents whose parents were more negative about their smoking were more likely to be smokers.

Cross-sectional analyses using only the initial triers produced 1 significant interaction involving grade (out of a possible 10). There was a significant interaction between grade and friends' attitudes $(F=10.88, p<.001)$. The effect of friends' attitudes generally increased with grade and was strongest at the 8th-9th grade level (betas of $.29, .59$, and .42 , respectively). In all cases, adolescents whose friends were more positive about their smoking were more likely to be smokers. Thus, when cross-sectional analyses were performed for initially homogeneous groups, few grade interactions were found. ${ }^{1}$

\section{Discussion}

We will discuss the current findings in relation to two important issues for adolescent development. First, we will describe how parent and peer influences affect an adolescent problem behavior (cigarette smoking). Second, we will consider whether or not these influences change with age-particularly whether peer influences increase with adolescence and whether there is a corresponding decrease in parental influence.

From our longitudinal analyses, it is clear that both peer and parent factors significantly predict future transitions in smoking status. The initial onset of smoking among never smokers was more likely for adolescents with more smoking friends and parents, for those who had lower levels of parental support, and for those whose friends had lower expectations for the subject's general and academic success. In addition, for the youngest never smokers, those with stricter parents were more likely to begin to smoke, suggesting a rebellion motive. For the oldest subjects, those with less strict parents were more likely to begin to smoke. The later transition from experimental to regular smoking was more likely among adolescents who had more smoking friends, lower levels of parental support, and higher levels of peer support. For girls, the transition to regular smoking was also more likely if their friends' had more positive attitudes toward their smoking and if their friends had lower expectations for the subjects' general and academic success. For boys, the transition to regular smoking was more likely if their friends had higher expectations for the subject's academic and general success. These findings are consistent with investigations of other substance-use behaviors (Chassin, 1984; Jessor \& Jessor, 1977), and they demonstrate that both parents and peers exert important influences on adolescent behaviors.

Sex differences were also observed in the effects of peer and parent influences on subsequent behaviors. When sex differences were found, the pattern of these differences showed that peer and parent influences were significant for girls but not for boys. These findings are consistent with previous research in substance use in suggesting that girls are more susceptible to outside social influence than are boys (Chassin, 1984; Huba \& Bentler, 1980).

The data thus indicate that both parents and peers exert significant influences on adolescent behavior despite popular conceptions of adolescents as dominated by their peers. However, the next important question concerns age-related differences in the magnitude of peer and parent influences. Some conceptions of adolescence as a developmental stage suggest that peer influences should increase in magnitude over this age period, although parent influences should decline in magnitude.

The current data produced two very different pictures of agerelated differences in parent and peer influence, depending on whether we looked cross sectionally or longitudinally. The crosssectional data precisely replicated previous research (e.g., Krosnick \& Judd, 1982) in showing age-related increases in the magnitude of peer influences. In addition, there was some evidence of a decrease in parental influence. Thus, if we relied only on cross-sectional data we might view adolescents as increasingly dominated by their peers, at least in terms of cigarette smoking as a specific problem behavior.

However, when longitudinal data were analyzed to examine more directly actual changes in smoking behavior, a very different picture was obtained. Longitudinal analyses revealed a striking absence of grade interactions. From the longitudinal data we would derive a picture of adolescence as an age period where both parent and peer influences on cigarette smoking as a problem behavior remained significant but constant in strength.

These conflicting pictures of social influence during adolescence raise an important methodological point for developmental

\footnotetext{
1 These cross-sectional analyses performed separately on initial never smokers and initial triers produced few grade interactions (compared to analyses performed on nevers, triers, and smokers combined). A possible explanation for the lack of interactions in these analyses as well as in the longitudinal analyses is the drop in statistical power that results when the sample size is lowered to analyze initial never smokers and triers, separately. To rule out this explanation, a random sample of subjects was drawn from the combined sample of never smokers, triers, and smokers. This random sample was drawn to be the size of the smallest group, and the cross-sectional analyses were rerun. Three significant grade interactions and 2 marginal $(p<.10)$ interactions out of a possible 10 were still obtained. This included the important significant interaction between grade and number of smoking friends obtained by Krosnick and Judd (1982). Thus, a simple drop in statistical power cannot account for the relative lack of grade interactions found for initial never smokers and initial triers analyzed separately.
} 
research. Cross-sectional data are unable to examine directly the onset of a behavior. Rather, a heterogeneous population is created when adolescents at different statuses (e.g., never smokers, triers, regular smokers) are compared in cross-sectional analyses. Crosssectional analyses are unable to consider how long a subject has been at a particular status. With regard to smoking, cross-sectional comparisons among smokers and nonsmokers do not consider whether the adolescent has just become a smoker or is a long-standing smoker. Thus, the factors that lead to smoking onset are confounded by the presence of these long-standing smokers. Cross-sectional analyses also confound the causes of smoking onset with the effects of smoking onset. It has been demonstrated that peer and parent influences not only prospectively predict adolescent smoking but, once an adolescent begins to smoke, there are consequent changes in peer and parent factors (Chassin, Presson, \& Sherman, 1984).

In short, typical cross-sectional analyses of smokers and nonsmokers confound the influences on recently initiated smokers with the influences on long-standing smokers. Using our data set, we were able to demonstrate the implications of this confounding by comparing cross-sectional prediction done with all subjects and cross-sectional prediction done with initially homogeneous groups (separately for initial never smokers and initial triers). When cross-sectional analyses were performed for initially homogeneous groups, age-related changes in peer and parent influences were no longer found. Thus, when analyses were performed on initially homogeneous groups, the cross-sectional analyses paralleled the longitudinal ones, confirming our longitudinal findings.

It is important to remember, however, that cross-sectional analyses cannot typically be performed on initially homogeneous groups. Only the longitudinal data allowed us to constitute these groups. One possible alternative for cross-sectional studies of transitions would be to ask subjects to report retrospectively on the timing of their transition. In this way, only recent initiators could be included in the cross-sectional analyses. Of course, given problems of retrospective data, longitudinal analyses are clearly preferable.

This distinction between longitudinal and cross-sectional findings is not a new one. In epidemiological and public health research, it is equivalent to the question of disease prevalence (investigating all individuals who have a disease at a given point in time) versus disease incidence (investigating new cases of a disease). Prevalence and incidence questions often produce conflicting data.

These differences between cross-sectional and longitudinal procedures must be clarified in order to explain the rather different results produced by the two approaches. In our longitudinal analyses, we include fewer and fewer subjects from the total population as grade level increases because long-term smokers at each grade level are dropped from the analyses. Thus, the longitudinal sample includes a more and more limited subsample with increasing grade level. Typical cross-sectional approaches, on the other hand, include all available subjects at every grade level. With increasing grade, therefore, cross-sectional samples include a greater percentage of long-term smokers as well as subjects who have smoked for longer and longer periods of time. Thus, smoking prevalance and smoking incidence are increasingly confounded with increasing grade level. The appropriateness of including these long-term smokers depends on the nature of the research question. When the basic purpose of the research is to isolate the factors that are important in transitions to higher levels of smoking, the inclusion of long-standing smokers is not appropriate.

This issue is relevant to the study of any phenomenon that develops at different rates for different members of a population (e.g., predicting marriage, death, incidence of disease). There are fewer and fewer subjects in the population eligible to make the transition later in time, and indeed the early-transition subjects may differ in significant ways from those who make the transition later or those who never make the transition. In the case of the present study, those who make early transitions to smoking are likely to be among the most deviance prone adolescents. They are thus most likely to have many friends who smoke, friends who have more positive attitudes toward smoking, and so forth. In addition, those who are long-term smokers are likely to undergo more and more changes over time that represent consequences of smoking (e.g., acquiring even more friends who smoke). With inclusion of more of these early-transition subjects at higher grades, the correlation between factors such as number of friends who smoke and smoking status should thus increase with grade-and the findings of Krosnick and Judd (1982) can be understood in this way. In fact, when the long-term smokers are eliminated, neither a cross-sectional analysis nor a longitudinal analysis finds that the association of smoking status (or transition to higher levels of smoking status) with parent or peer factors changes with grade.

In sum, the current data are important in two respects. First, they point to the continuing importance of both peer and parent influences on smoking transition over early and middle adolescence. Furthermore, in contrast to previously reported findings, the magnitude of parent and peer influences did not vary over the 6 th- 11 th grade levels. Second, the data point to the limitations of cross-sectional designs for the study of developmental transitions. Important differences between the results and implications of longitudinal and cross-sectional designs were identified. The understanding of these differences is important for other research involving transitions in substance-use behaviors as well as in other transitions over the life span.

\section{References}

Ausubel, D. P., Montemayor, R., \& Svajian, P. (1977). Theories and problems of development. New York: Grune \& Stratton.

Berndt, T. J. (1979). Developmental changes in conformity to peers and parents. Developmental Psychology, 15, 608-616.

Biddle, B. J., Bank, B. J., \& Marlin, M. M. (1980a). Parental and peer influences on adolescents. Social Forces, 58, 1057-1079.

Biddle, B. J., Bank, B. J., \& Marlin, M. M. (1980b). Social determinants of adolescent drinking: What they think, what they do, and what $I$ think and do. Journal of Studies on Alcohol, 4I, 215-241.

Brittain, C. (1963). Adolescent choices and parent-peer cross pressures. American Sociological Review, 28, 385-391.

Brody, G. H., \& Shaffer, D. R. (1982). Contributions of parents and peers to children's moral socialization. Developmental Review, 2, 31-75.

Chassin, L. (1984). Adolescent substance use and abuse. In P. Karoly \& J. Steffen (Eds.), Advances in child behavior analysis and therapy (Vol. 3, pp. 99-152). Lexington, MA: Heath.

Chassin, L., Presson, C. C., Bensenberg, M., Corty, E., Olshavsky, R., \& 
Sherman, S. J. (1981). Predicting adolescents' intentions to smoke cigarettes. Journal of Health and Social Behavior, 22, 445-455.

Chassin, L., Presson, C. C., \& Sherman, S. J. (1984). Cigarette smoking and adolescent psychosocial development. Basic and Applied Social Psychology, 5, 295-315.

Chiriboga, D. A. (1984). The longitudinal study of transitions. In S. Mednick, M. Harway, \& K. Finello (Eds.), Handbook of longitudinal research: Vol. 2. Teenage and Adult Cohorts (pp. 340-355). New York: Praeger.

Clasen, D. R., \& Brown, B. B. (1985, April). The multidimensionality of peer pressure in adolescence. Paper presented at the biennial meeting of the Society for Research in Child Development, Toronto, Canada.

Clayton, R. R. (1979). The family and federal drug abuse policies-programs: Toward making the invisible family visible. Journal of Marriage and the Family, 637-647.

Evans, R., Hansen, W., \& Mittlemark, M. (1977). Increasing the validity of self-reports of smoking behavior in children. Journal of Applied Psychology, 62, 521-523.

Everitt, B. S., \& Dunn, G. (1983). Advanced methods of data exploration and modelling. London: Heinemann.

Flay, B., d'Avernas, J., Best, J. A., Kersall, M., \& Ryan, K. (1983). Cigarette smoking: Why young people do it and ways of preventing it. In P. J. McGrath \& P. Firestone (Eds.), Pediatric and adolescent behavioral medicine (pp. 132-183). New York: Springer-Verlag.

Glynn, T. J. (1981). From family to peer: A review of transitions of influence among drug-using youth. Journal of Youth and Adolescence, $10,363-383$.

Huba, G. J., \& Bentler, P. M. (1980). The role of peer and adult models for drug taking at different stages in adolescence. Journal of Youth and Adolescence, 9, 449-465.
Jessor, R., \& Jessor, S. L. (1977). Problem behavior and psychosocial development: A longitudinal study of youth. New York: Academic Press.

Josephson, E., \& Rosen, M. (1978). Panel loss in a high school drug study. In D. B. Kandel (Ed.), Longitudinal research on drug use: Empirical studies and methodological issues (pp. 115-133). New York: Wiley.

Kandel, D. B., \& Lesser, G. S. (1972). Youth in two worlds. San Francisco: Jossey-Bass.

Kriska, S. D., \& Milligan, G. W. (1982). Multiple regression analysis for categorical data with an illustrative application in personnel selection. Psychological Bulletin, 92, 193-202.

Krosnick, J. A., \& Judd, C. M. (1982). Transitions in social influence at adolescence: Who induces cigarette smoking? Developmental Psychology, 18, 359-368.

Leventhal, H., \& Cleary, P. (1980). The smoking problem: A review of the research and theory in behavioral risk modification. Psychological Bulletin, 88, 370-405.

Levitt, E. E. (1971). Reasons for smoking and not smoking given by school children. Journal of School Health, 4l, 101-105.

Pedhazur, E. J. (1982). Multiple regression in behavior research: Explanation and prediction. New York: Holt, Rinehart, \& Winston.

Schlegel, R. P., \& DiTecco, D. (1978). Mediational adequacy of the Fishbein model under conditions of varying behavioral complexity. Unpublished manuscript, University of Waterloo, Ontario, Canada.

Received July 29,1985

Revision received November 27, 1985 